\title{
Valuation and Appreciation of Biodiversity: The "Maintenance of Options" Provided by the Variety of Life
}

\author{
Daniel P. Faith* \\ The Australian Museum Research Institute, The Australian Museum, Sydney, NSW, Australia
}

OPEN ACCESS

Edited by:

Martin F. Quaas,

Leipzig University, Germany

Reviewed by:

László Erdős,

Centre for Ecological Research,

Hungarian Academy of Sciences,

Hungary

Bartosz Bartkowski,

Helmholtz Centre for Environmental

Research (UFZ), Germany

${ }^{*}$ Correspondence:

Daniel P. Faith

dan.faith@austmus.gov.au

Specialty section:

This article was submitted to

Conservation and Restoration

Ecology,

a section of the journal

Frontiers in Ecology and Evolution

Received: 30 November 2020

Accepted: 15 March 2021

Published: 16 April 2021

Citation:

Faith DP (2021) Valuation and Appreciation of Biodiversity: The "Maintenance of Options"

Provided by the Variety of Life.

Front. Ecol. Evol. 9:635670.

doi: 10.3389/fevo.2021.635670
"Nature's contributions to people" (NCP) is an important expansion beyond the standard ecosystem services framework, particularly as a pathway to better address global/regional biodiversity values. NCP18, "maintenance of options," refers broadly to the capacity of ecosystems, habitats, species, or genotypes to keep options open to support a good quality of life. "Biodiversity," interpreted as living variation, is an important, but under-appreciated, aspect of "maintenance of options." IPBES refers to "the "option values of biodiversity," that is, the value of maintaining living variation in order to provide possible future uses and benefits." IPBES assessments include biodiversity option value, and use phylogenetic diversity (PD) as an indicator of change in status of NCP18. At the same time, IPBES notes the need for greater appreciation of option values of biodiversity. Popular ecosystem services framings forget the long history of consideration of these global benefits of biotic diversity to humanity, and their normative links. Popular ecological definitions mean that many current valuations of "biodiversity" neglect the benefits of biodiversity-as-variety. Economic valuations of "biodiversity" typically have focused on ecosystem aspects, not variety; related ecosystems framings value "biodiversity" with a focus on those critical elements relating to functioning of ecosystems. Greater appreciation of biodiversity option value and NCP18 may depend on clearer messaging from academia, better highlighting of the link between biodiversity and intergenerational justice, and greater communication of stories of past surprising discoveries of benefits from species that highlight biodiversity as an ongoing source of future benefits. An important pathway for better appreciation of insurance and investment benefits of variety is to understand and communicate the reasons why we value these benefits from variety. Biodiversity-as-variety is valued because we care about the welfare of future generations.

Keywords: biodiversity, phylogenetic diversity, IPBES, option value, value, maintenance of options, nature's contributions to people

\section{INTRODUCTION}

The term "Nature's contributions to people" (NCP) refers to all the positive and negative contributions of living nature to people's good quality of life (Díaz et al., 2018). This broad NCP framing has been used extensively in the Intergovernmental Platform for Biodiversity and Ecosystem Services (IPBES) Regional and Global assessments, and NCP is the basis for a major 
goal of the Convention on Biological Diversity (CBD) post-2020 framework ${ }^{1}$. The urgent need to maintain NCP prompted the IPBES Global assessment to call for "transformative change" - a fundamental reorganization across technological, economic, and social factors, including values, as needed to achieve goals for conserving and sustainably using nature (IPBES, 2019).

This article is a contribution to a Frontiers research topic, examining how transformative change supporting nature's contributions to people can build on valuation, increased awareness, and concrete actions. The goal of this article is to explore these themes for one of the most challenging of the NCP, "Maintenance of options" ("NCP18"). While progress has been made in recognizing this NCP and its link to biodiversity option value, here I hope to provide further progress by suggesting some under-explored potential pathways to address the current limitations in its appreciation.

The 18 different NCP categories cover many aspects of "nature" and many ways to think about its "contributions" (Díaz et al., 2018). This article will focus specifically on "biodiversity" interpreted, following early historical discussions of biotic diversity and its value (see Faith, 2017a, 2021), as living variation at multiple levels. Linking the term "biodiversity" specifically to variety allows a critical focus here on challenges of valuation, appreciation, and actions in this fundamental context - and how this may contribute to transformative change.

This perspective is relevant to the CBD Vision to better appreciate the value of biodiversity and to halt its loss. This reference to biodiversity "loss" acknowledges the biodiversity crisis and loss of living variation. The CBD post-2020 global biodiversity framework "sets out an ambitious plan to implement broad-based action to bring about a transformation in society's relationship with biodiversity ..." (CBD/WG2020/2/3). Importantly, the CBD post-2020 framework includes an explicit goal to maintain Nature's Contributions to People (see text footnote 1).

Among the $18 \mathrm{NCP}$, one stands out as particularly relevant to the contribution to people arising from biodiversity-asvariety. "Maintenance of options" ("NCP18") is described (Díaz et al., 2018) as the "Capacity of ecosystems, habitats, species or genotypes to keep options open in order to support a good quality of life." This may include contributions both from individual elements and from variety itself. IPBES assessments have referred to "Maintenance of options" as capturing a fundamental benefit/value related to biodiversity-as-variety. The IPBES conceptual framework (Díaz et al., 2015) refers to this as: "The "option values of biodiversity," that is, the value of maintaining living variation in order to provide possible future uses and benefits" (for review, see Faith, 2017a, 2021). I note that early work, summarized in IUCN (1980), highlighted two values of variety that link to maintenance of options, called "insurance and investment." Biodiversity option value - the focus of this article - is a kind of investment value, while insurance value relates more to the way in which variety serves in responding to environmental changes (for reviews, see Bartkowski, 2017; Faith, 2017a, 2021).

\footnotetext{
${ }^{1}$ https://www.cbd.int
}

Several IPBES assessments have discussed biodiversity option value under NCP18 (IPBES, 2018b). The IPBES Asia Pacific Regional Assessment (“AP”) concluded:

\begin{abstract}
"The NCP "Maintenance of options" (NCP18) accords well with the IPBES Conceptual Framework listing of anthropocentric values including "the option values of biodiversity as a reservoir of yetto-be discovered uses from known and still unknown species and biological processes" (Díaz et al., 2015). Because these benefits are typically global, they are distinguished from others within-ecosystem benefits.... NCP18 refers to "Benefits (including those of future generations) associated with the continued existence of a wide variety of species, populations and genotypes." "Wide variety" is another way of saying "biodiversity." Thus, this statement echoes early discussions that identified biodiversity itself as providing a benefit corresponding to maintenance of options"
\end{abstract}

Significantly, this assessment found support for biodiversity option value in early discussions of "biotic diversity", which preceded the actual coining of term "biodiversity" around 1985 (for reviews, see Mazur and Lee, 1993; Faith, 2017a). For example, Haskins (1974) summarized a meeting where participants called for "an Ethic of Biotic Diversity in which such diversity is viewed as a value in itself and is tied in with the survival and fitness of the human race." Haskins linked this to biodiversity option value: "Plants and animals that may now be regarded as dispensable may 1 day emerge as valuable resources." Thus, his phrase "value in itself" was not a reference to intrinsic value but to the idea that variety "in itself" is valuable to people. Myers (1976) similarly argued that "loss of species will affect generations into the indefinite future, whose options to utilize species in ways yet undetermined should be kept open." IUCN (1980) summarized such foundational discussions: "we may learn that many species that seem dispensable are capable of providing important products, such as pharmaceuticals. .."

The IPBES regional assessment report for Europe and Central Asia ("ECA"; IPBES, 2018c) and the IPBES Global Assessment (IPBES, 2019) also discussed biodiversity option value under NCP18, and these assessments adopted an informative measure of biodiversity in this context, called "phylogenetic diversity (PD)" (Faith, 1992). The ECA concluded "The maintenance of options is a contribution that depends on the existence of biodiversity, and its status and trends are reflected by those of biodiversity measures, including PD."

While any measure of biodiversity as variety can be linked to biodiversity option value (Faith, 2017a), "phylogeny" (the evolutionary "tree of life") is naturally informative about the variety of evolutionary features that may prove beneficial in the future. Phylogenetic diversity is a form of biodiversity, because it indicates the variety of units (broadly, the full range of different evolutionary features of a nominated set of species; Faith, 1992). Technically, PD is quantified as the sum of phylogenetic "branch lengths" (typically measured in millions of years) spanning a set of species. PD is a useful indicator of biodiversity option value because the corresponding feature diversity (including features not currently known) preserves the possibility of future surprising benefits (Faith, 1992). An example study documented how three different traditional cultures (in Nepal, New Zealand, 
and Cape of South Africa) independently have used the same plant medicinal property - a feature that evolved in the shared ancestor of the three different plant species found in the three different regions (Saslis-Lagoudakis et al., 2012). The sharing of the same useful medicinal evolutionary feature among distant peoples illustrates how a feature from the tree of life may be a global public good (see Rands et al., 2010).

The IPBES definition of "biodiversity" reflects this idea of phylogeny and feature diversity, in referring to the variety of phylogenetic "attributes": "The variability among living organisms from all sources ... This includes variation in genetic, phenotypic, phylogenetic, and functional attributes...." The IPBES Global assessment reported estimated expected PD losses, over multiple taxonomic groups, as an indicator of the changing status of this biodiversity option value aspect of maintenance of options. This indicated a decline in NCP18, as part of the reporting of global trends in the capacity of nature to sustain contributions to good quality of life from 1970 to the present (Figure 1 in Díaz et al., 2019a). Key message 3 of the assessment concluded: “.... some contributions of nature are irreplaceable (well established). Loss of diversity, such as phylogenetic and functional diversity, can permanently reduce future options ..." This IPBES PD indicator (Faith et al., 2018) also has been proposed for the CBD post-2020 global biodiversity framework (CBD/SBSTTA/24/3Add.1) as an indicator to monitor progress in addressing biodiversity option value aspects of NCP18, within the broader CBD goal to value and conserve nature's contributions to people.

Significantly, the IPBES assessments also noted limitations in the appreciation of these values. The ECA concluded "Society's appreciation of maintenance of options is only moderate, as indicated by previous assessments of Europe and Central Asia, and by the recent call for greater appreciation of maintenance of options from conservation NGOs" (see Gascon et al., 2015; Faith, 2017a).

The AP discussed these challenges, noting that the Biodiversity Barometer (2015) report for Asia-Pacific countries found that,

\begin{abstract}
"respondents from these countries had low scores when asked to define "biodiversity" demonstrating their lack of understanding that it means "living variation." Understanding the definition is foundational for a community appreciation of the idea that biodiversity provides maintenance of options. The shift in focus by IPBES from "ecosystem services" to NCP helps to overcome the neglect of the typically global-scale option values of biodiversity."
\end{abstract}

This echoes the argument (IPBES, 2018a) that,

"It has to be recognized that the concept of "nature's contributions to people" has evolved in a context where challenges related to the loss of biodiversity are addressed and assessed on global and regional levels. The implications of this widening from the ecosystem service framework ... is largely an issue that remains to be explored."

This background sets the stage for the following two sections of this article. First, I discuss the challenges in increasing appreciation of biodiversity and NCP18. Then, I consider

$\overline{{ }^{2} \text { https://ipbes.net/glossary/biodiversity }}$ possible pathways to increase awareness of the value of the biodiversity option value aspect of NCP18.

\section{CHALLENGES}

Biodiversity option value, as a benefit and value of variety, has strong roots in early historical arguments about biotic diversity (Faith, 2021). Given this history, we might expect greater current appreciation of this core value of variety. Bartkowski (2019) argues that, in reality, discussions of values of "biodiversity" typically have focused on individual elements, with the lessattention to the actual values of variety itself, including both option and insurance values (for review, see Faith, 2017a, 2021).

The IPBES assessments suggest that distinctions between ecosystem services and NCP framings may help to explain this neglect. Ecosystems provide many services to people (clean water, etc.), and these benefits naturally suggest one case for conservation of "biodiversity". The ecosystems framing adopts the perspective that "biodiversity" is the basis for these important ecological functions and services. This gains support through ecological diversity definitions of "biodiversity" thus, linking, by definition, to ecological factors that are important for ecosystem services (see Faith, 2017a, 2018). For example, the Routledge Handbook of Ecosystem Services says: "Biodiversity broadly encompasses the number, abundances, functional variety, spatial distribution, and interactions of genotypes, species, populations, communities, and ecosystems" (Balvanera et al., 2016). This inclusion of many aspects of ecology may distract from the core idea of biodiversity as variety (Faith, 2017a).

Such ecological definitions in turn are reflected in the statements about value and valuation of biodiversity (including PD), implying less emphasis on the global scale option value provided by variety of species or other elements. For example, the Encyclopedia of Biodiversity chapter on "The Value of Biodiversity" (Dasgupta et al., 2013), claims that: "The value of biodiversity derives from the value of the final goods and services it produces. To estimate this value, one needs to understand the "production functions' that link biodiversity, ecosystem functions, ecosystem services, and the goods and services that enter into final demand."

The within-ecosystems focus, and neglect of global biodiversity option value, sometimes has been supported by an historical accounting, in which "biodiversity" was all about intrinsic value until the ecosystem services framing forged links to anthropocentric values (for discussion, see Faith, 2017a, 2018). For example, Reyers et al. (2012) envision improved biodiversity conservation: ". . . by adopting the concept of ecosystem services and by arguing that the conservation of biodiversity matters not only because of its intrinsic value but because it is essential for human well-being". Thus, a lack of appreciation of the long-standing arguments for global biodiversity option value makes it appear that ecosystem services is the only basis for anthropocentric values of biodiversity.

A risk in focusing on local ecosystem values of different elements or aspects of ecosystems (all called values of 
"biodiversity") is that we lose track of the value of variety at the global scale. For example, Pascual (2020) constructively focused on integrating diverse values of different people, by considering the many different values for what he called "aspects" of biodiversity. This strategy broadly captures local values of aspects of nature, but may neglect the value of global biodiversity as variety. Owen et al. (2019) present an analysis illustrating how a conservation focus on functional traits and services within ecosystems could lead to the global loss of PD and its option values. A challenge is to recognize that there are costs and tradeoffs among competing local to global conservation goals, and that this requires planning that integrates global option value with other goals (Pollock et al., 2017).

Conservation for global biodiversity option value requires that it be "on the table" along with other goals. Faith (2017b) reviewed case studies in which an ecosystem focus and neglect of global biodiversity option values determined corresponding limitations of conservation actions (e.g., regional planning). Faith contrasted these with early planning case studies that successfully integrated more localized (ecosystem and other) values with global biodiversity option value. The IPBES assessments, and other discussions of NCP, call for similar integrated broad recognition of multiple benefits/values of nature as part of transformational change. Transformational change supporting such integrated planning would benefit greatly from increased appreciation of the biodiversity option value associated with NCP18. In the next section, I sketch three potential pathways that might increase such appreciation.

\section{PATHWAYS}

\section{Clearer Messaging From Academia Can Produce Clearer Messages for Decision-Makers}

Some popular presentations of NCP obscure important aspects of NCP18. For example, Peterson et al.'s (2018) critique of NCP referred to "maintenance of options," as "the capacity of ecosystems to keep options open in order to support a good quality of life" (Díaz et al., 2018: SM)." Peterson et al. (2018) misquoted the Díaz et al., description of "Maintenance of options" as the "Capacity of ecosystems, habitats, species or genotypes to keep options open." The misrepresentation gives the impression that the maintenance of options is only about how ecosystems support human-well-being (for discussion, see Faith, 2018).

The influential Global Biodiversity Outlook 5 (Secretariat of the Convention on Biological Diversity, 2020) imposes a similar equation of NCP with ecosystem services: "most ecosystem services (nature's contributions to people) are in decline." Further, the report misrepresents the key Figure 1 legend of the IPBES Global SPM ("Global trends in the capacity of nature...") as "Global trends... in the capacity of ecosystems..." This misrepresentation under-mines appreciation that the capacity of the global tree of life phylogenetic diversity is a contribution that spans many locations/ecosystems in providing the global biodiversity option value of NCP18.

A major review (Kadykalo et al., 2019) compared ecosystem services and NCP framings, concluding that "the generalizing perspective of the NCP framework provides no great addition beyond what has already been done in terms of classification in ES research." This appears to reflect a conventional ecosystemservices-based interpretation of "biodiversity." The first phrase of their article is: "People depend on functioning ecosystems..." and they refer to "living systems (i.e., biodiversity in its broadest sense)". Kadykalo et al. (2019) did not discuss the existing conceptual issues about the option value of biodiversity-asvariety (Faith, 2018), under their discussion of "Conceptual Claims which distinguish NCP from ES."

Greater awareness, and appreciation, of biodiversity option value will benefit from clearer consistent presentation of NCP, including discussion of the contributions to people from global biodiversity.

\section{Intergenerational Justice Considerations Increase Appreciation of Biodiversity Option Value}

Díaz et al. (2019b) noted a relevant leveraging point for enabling transformative change: "unleashing existing, widely held values of responsibility to effect new social norms for sustainability." A sense of responsibility to future generations is widely held, and this may help effect a social norm about preserving biodiversity's maintenance of options. The early discussions of the value of biotic diversity critically linked to ideas about ethics, and justice for future generations (reviewed in Faith, 2017a, 2021), and this supported appreciation of biodiversity option value. Building on these early discussions, the Brundtland Report's (WCED, 1987) discussion of "sustainable development" stated a requirement: "The loss of plant and animal species can greatly limit the options of future generations; so sustainable development requires the conservation of plant and animal species." That requirement indicates a normative obligation with regard to our relationships with future generations.

Similarly, Schroeder and Pisupati (2010) argued that the core objective of the Convention on Biological Diversity, the conservation of biodiversity, is about attaining intergenerational justice. They concluded that "to deplete the planet of essential resources and leave to future generations a world which severely limits their options, is unjust." This argument highlights how biodiversity has a current value to society because we care about the welfare of future generations.

These normative justifications for biodiversity option value accord with Chan and Satterfield (2020) arguments that: "policymakers should think of values as not only the outputs of valuation, but also the preferences, principles and virtues that people have about relationships involving nature (relational values, Chan et al., 2016)."

Faith (2017a) links biodiversity's maintenance of options to a kind of relational value, relating the present generation to future generations: "the best argument for what we call the option value of biodiversity is that we see many currently 
beneficial units, and maintaining a large number of units (biodiversity) for the future will help maintain a steady flow of such beneficial units... Biodiversity option value therefore links "variation" and "value": providing a fundamental relational value of biodiversity reflecting our degree of concern about benefits for future generations."

This perspective may overcome the miss-perception that NCP18, maintenance of options, does not enter into assessments of current well-being, because all the benefits are in the future. For example, Brauman et al. (2020), in their assessment of links between NCP and well-being, argue "We do not provide results across the types of contribution for habitat creation and maintenance of options; their influence on quality of life is felt through their role supporting other contributions of nature." In contrast, the idea that there is a relational value of biodiversity, reflecting our degree of concern about benefits for future generations, opens the door to appreciating the maintenance of options provided by biodiversity as a contributor to our current quality of life.

\section{Stories About Surprising Discoveries}

Increased awareness and appreciation of maintenance of options can build on our awareness of many currently beneficial species. This promotes an appreciation that retaining biodiversity for the future will help maintain the ongoing discovery of such benefits. Chan and Satterfield (2020) suggest that "we need to focus more on stories. quotes, images and videos that viscerally express value, and more directly engage audiences." Greater appreciation of biodiversity option value therefore may be found in stories about surprising discoveries of useful species.

IPBES assessments not only reported expected loss of PD (Faith et al., 2018), but also provided some recent stories, in each region, about recent surprising discoveries of benefits from the tree of life. The IPBES ECA concluded: "Phylogenetic diversity (Faith, 1992) over multiple taxonomic groups is also an informative metric of the capacity of biodiversity to deliver maintenance of options ....... The appreciation for this contribution from nature to people is also found in the greater awareness of recent unanticipated benefits from biodiversity...." The ECA stories included the "un-expected global benefit" emerging from the discovery that a moth caterpillar can eat through plastic (Bombelli et al., 2017). Another story reported "the recent published role of golden jackals (C. aureus), long regarded as a pest, as a remover of domestic animal carcasses". Similarly, the IPBES AP reported the recent discovery that the venom of the Australian funnel web spider (Hadronyche infensa)

\section{REFERENCES}

Balvanera, P., Quijas, S., Martín-López, B., Barrios, E., Dee, L., Isbell, F., et al. (2016). "The links between biodiversity and ecosystem services," in Routledge Handbook of Ecosystem Services, eds M. Potschin, R. Haines-Young, R. Fish, and R. K. Turner (London: Taylor \& Francis Group).

Bartkowski, B. (2017). Are diverse ecosystems more valuable? Economic value of biodiversity as result of uncertainty and spatial interactions in ecosystem service provision. Ecosyst. Serv. 24, 50-57. doi: 10.1016/j.ecoser.2017. 02.023 is the unlikely source for a drug to ward off brain damage caused by strokes.

The ECA concluded that "The appreciation and value of this contribution from nature to people can also be estimated through the ongoing reporting of surprising discoveries in the popular press. For example, the golden jackals' example was widely communicated through a New Scientist article. Such examples can reinforce people's relational value, linking biodiversity to future generations' quality of life...."

While such stories were seen as important, the IPBES assessments found that, for a given region, there was no clear source of such stories of recent discoveries of benefits. A growing collection of such examples would boost awareness of option value of biodiversity. Further, such collections, for different taxonomic groups, may allow a way to test the link between PD and biodiversity option value. For example, Forest et al. (2007) used a compendium listing all the known human uses of flowering plants in South Africa's Cape Floristic Region, and asked 'if we did not know these uses, would maintaining the PD of this group have been a good strategy for keeping options open to find these uses?' The study found that conservation of PD significantly maintained the opportunity to discover these future benefits.

The Forest et al. (2007) study suggests that appreciation of biodiversity (PD) option value will continue to be found through two kinds of phylogenetic observations. First, we see that alreadyknown uses/benefits that are shared by species typically reflect the species' shared ancestry - the shared feature can be explained by shared ancestry (as in the plants example above). Second, we see that surprising benefits continue to be found throughout the tree of life. It is this PD that ensures possible future benefits. These observations in combination can help to appreciate the core of biodiversity option value - it is not about already-known uses (we can target those species directly); it is about how variety maintains the prospect of surprising new uses.

I conclude that, within NCP18, biodiversity's maintenance of options can help motivate the needed transformative change to conserve global biodiversity. That role is based on a greater appreciation of the core idea that variety itself has value, and that we are ethically obliged to preserve this variety for future generations.

\section{AUTHOR CONTRIBUTIONS}

The author confirms being the sole contributor of this work and has approved it for publication.

Bartkowski, B. (2019). "Valuation of biodiversity," in Oxford Research Encyclopedia of Environmental Science, ed J. Kahn (Oxford: Oxford University Press), doi: 10.1093/acrefore/9780199389414.013.459

Biodiversity Barometer (2015). UEBT Biodiversity Barometer 2009-2015. Available online at: https://www.dropbox.com/s/8i7pd85xxdr1s37/UEBT\% 20Biodiversity\%20Barometer\%202015-\%20English.pdf?dl=1 (accessed November 2020).

Bombelli, P., Howe, C. J., and Bertocchini, F. (2017). Polyethylene bio-degradation by caterpillars of the wax moth Galleria mellonella. Curr. Biol. 27, R292-R293. doi: 10.1016/j.cub.2017.02.060 
Brauman, K. A., Garibaldi, L. A., Polasky, S., Aumeeruddy-Thomas, Y., Brancalion, P. H. S., DeClerck, F., et al. (2020). Global trends in nature's contributions to people. Proc. Natl. Acad. Sci. U.S.A. 117, 32799-32805. doi: 10.1073/pnas. 2010473117

Chan, K. M. A., Balvanera, P., Benessaiah, K., Chapman, M., Díaz, S., Gould, R., et al. (2016). Why protect nature? Rethinking values and the environment. PNAS 113, 1462-1465. doi: 10.1073/pnas.1525002113

Chan, K. M. A., and Satterfield, T. (2020). The maturation of ecosystem services: social and policy research expands, but whither biophysically informed valuation? People Nat. 20, 1021-1060. doi: 10.1002/pan3.10137

Dasgupta, P., Kinzig, A. P., and Perrings, C. (2013). "The value of biodiversity," in Encyclopedia of Biodiversity, 2nd Edn, 7, ed. S. A. Levin (Waltham, MA: Academic Press), 167-179. doi: 10.1016/B978-0-12-3847-19-372-375

Díaz, S., Demissew, S., Carabias, J., Joly, C., Lonsdale, M., Ash, N., et al. (2015). The IPBES conceptual framework - connecting nature and people. Curr. Opin. Environ. Sustain. 14, 1-16. doi: 10.1016/j.cosust.2014.11.002

Díaz, S., Settele, J., Brondízio, E., Ngo, H., Guèze, M., Agard, J., et al. (2019a). Summary for Policymakers of the Global Assessment Report on Biodiversity and Ecosystem Services. Bonn: Intergovernmental Science-Policy Platform on Biodiversity and Ecosystem Services.

Díaz, S., Pascual, U., Stenseke, M., Martín-López, B., Watson, R. T., Molnár, Z., et al. (2018). Assessing nature's contributions to people. Science 359, 270-272.

Díaz, S., Settele, J., Brondízio, E. S., Ngo, H. T., Agard, J., Arneth, A., et al. (2019b). Pervasive Human-Driven Decline of Life on Earth Points to the Need for Transformative Change. Available online at: http://science.sciencemag.org/ content/suppl/2019/12/11/366.6471.eaax3100.DC1 (accessed October 2020).

Faith, D. P. (1992). Conservation evaluation and phylogenetic diversity. Biol. Conserv. 61, 1-10. doi: 10.1016/0006-3207(92)91201-3

Faith, D. P. (2017a). "A general model for biodiversity and its value," in The Routledge Handbook of Philosophy of Biodiversity, eds J. Garson, A. Plutynski, and S. Sarkar (London: Routledge), 69-85.

Faith, D. P. (2017b). Ecosystem services can promote conservation over conversion and protect local biodiversity, but these local win-wins can be a regional disaster. Aust. Zool. 38, 477-487. doi: 10.7882/AZ.2014.031

Faith, D. P. (2018). Avoiding paradigm drifts in IPBES: reconciling "nature's contributions to people," biodiversity, and ecosystem services. Ecol. Soc. 23:40. doi: 10.5751/ES-10195-230240

Faith, D. P. (2021). "Biodiversity," in The Stanford Encyclopedia of Philosophy (Spring 2021 Edition), ed. E. N. Zalta (Stanford: Stanford University).

Faith, D. P., Veron, S., Pavoine, S., and Pellens, R. (2018). "Indicators for the expected loss of phylogenetic diversity," in Phylogenetic Diversity: Applications and Challenges in Biodiversity Science, eds R. A. Scherson and D. P. Faith (Berlin: Springer International Publishing), 73-91. doi: 10.1007/978-3-319-93145-6_4

Forest, F., Grenyer, R., Rouget, M., Davies, T. J., Cowling, R. M., Faith, D. P., et al. (2007). Preserving the evolutionary potential of floras in biodiversity hotspots. Nature 445, 757-760. doi: 10.1038/nature05587

Gascon, C., Brooks, T. M., Contreras-MacBeath, T., Heard, N., Konstant, W., Lamoreux, J., et al. (2015). The importance and benefits of species. Curr. Biol. 25, R431-R438.

Haskins, C. (1974). Scientists talk of the need for conservation and an ethic of biotic diversity to slow species extinction. Science 184, 646-647. doi: 10.1126/science. 184.4137 .646

IPBES (2018a). Background Document: Nature's Contributions to People. Watson B, IPBES Consultation and Capacity Building Workshop, 4-6 June 2018. Objective 2: Nature's Contribution to People. Bonn: IPBES.

IPBES (2018b). The IPBES Regional Assessment Report on Biodiversity and Ecosystem Services for Asia and the Pacific, eds M. Karki, S. Senaratna Sellamuttu, S. Okayasu, and W. Suzuki, Bonn: Secretariat of the Intergovernmental Science-Policy Platform on Biodiversity and Ecosystem Services.
IPBES (2018c). The IPBES Regional Assessment Report on Biodiversity and Ecosystem Services for Europe and Central Asia, eds M. Rounsevell, M. Fischer, A. Torre-Marin Rando, and A. Mader, Bonn: Secretariat of the Intergovernmental Science-Policy Platform on Biodiversity and Ecosystem Services.

IPBES (2019). The IPBES Global Assessment Report on Biodiversity and Ecosystem Services. Bonn: Secretariat of the Intergovernmental Science-Policy Platform on Biodiversity and Ecosystem Services.

IUCN (1980). World Conservation Strategy: Living Resource Conservation for Sustainable Development. Gland: International Union for Conservation of Nature [IUCN].

Kadykalo, A. N., López-Rodriguez, M. D., Ainscough, J., Droste, N., Ryu, H., Ávila-Flores, G., et al. (2019). Disentangling 'ecosystem services' and 'nature's contributions to people'. Ecosyst. People 15, 269-287. doi: 10.1080/26395916. 2019.1669713

Mazur, A., and Lee, J. (1993). Sounding the global alarm: environmental issues in the US national news. Soc. Stud. Sci. 23, 681-720. doi: 10.1177/ 030631293023004003

Myers, N. (1976). An expanded approach to the problem of disappearing species. Science 193, 198-202. doi: 10.1126/science.193.4249.198

Owen, N. R., Gumbs, R., Gray, C. L., and Faith, D. P. (2019). Global conservation of phylogenetic diversity captures more than just functional diversity. Nat. Commun. 10:859. doi: 10.1038/s41467-019-08600-8

Pascual, U. (2020). "Why do we need a more pluralistic approach to valuing biodiversity?", in Proceedings of the 'Seeds of Change: Provocations for a New Research Agenda' Biodiversity Revisited Symposium Conference Proceedings, 11 13 September 2019, eds C. Wyborn, N. Kalas, and N. Rust Vienna, doi: 10.13140/ RG.2.2.22170.59848/3

Peterson, G. D., Harmáčková, Z. V., Meacham, M., Queiroz, C., Jiménez-Aceituno, A., Kuiper, J. J., et al. (2018). Welcoming different perspectives in IPBES: "nature's contribution to people" and "ecosystem services". Ecol Soc. 23:39. doi: 10.5751/es-10134-230139

Pollock, L., Thuiller, W., and Jetz, W. (2017). Large conservation gains possible for global biodiversity facets. Nature 546, 141-144. doi: 10.1038/nature22368

Rands, M. R. W., Adams, W. M., Bennun, L., Butchart, S. H. M., Clements, A., Coomes, D., et al. (2010). Biodiversity conservation: challenges beyond 2010 . Science 329, 1298-1303. doi: 10.1126/science.1189138

Reyers, B., Polasky, S., Tallis, H., Mooney, H. A., and Larigauderie, A. (2012). Finding a common ground for biodiversity and ecosystem services. Bioscience 62, 503-507. doi: 10.1525/bio.2012.62.5.12

Saslis-Lagoudakis, C. H., Savolainen, V., Williamson, E. M., Forest, F., Wagstaff, S. J., Baral, S. R., et al. (2012). Phylogenies reveal predictive power of traditional medicine in bioprospecting. Proc. Natl. Acad. Sci. U.S.A. 109, 1583515840.

Schroeder, D., and Pisupati, B. (2010). Ethics, Justice and the Convention on Biological Diversity. Nairobi: United Nations Environmental Program.

Secretariat of the Convention on Biological Diversity (2020). Global Biodiversity Outlook 5. Montreal: Secretariat of the Convention on Biological Diversity. WCED (1987). Our Common Future. Oxford: Oxford University Press.

Conflict of Interest: The author declares that the research was conducted in the absence of any commercial or financial relationships that could be construed as a potential conflict of interest.

Copyright (C) 2021 Faith. This is an open-access article distributed under the terms of the Creative Commons Attribution License (CC BY). The use, distribution or reproduction in other forums is permitted, provided the original author(s) and the copyright owner(s) are credited and that the original publication in this journal is cited, in accordance with accepted academic practice. No use, distribution or reproduction is permitted which does not comply with these terms. 